\title{
Microstructural Changes Due to Laser Surface Melting of an AISI
}

\section{Stainless Steel}

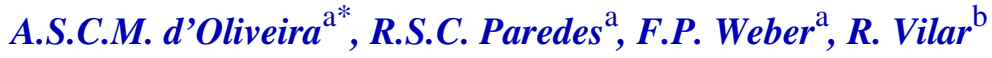 \\ ${ }^{a}$ Departamento de Engenharia Mecânica, Universidade Federal do Paraná, \\ 81531990 Curitiba - PR, Brazil \\ ${ }^{\mathrm{b}}$ Departamento de Engenharia de Materiais, Instituto Superior Técnico, \\ Lisboa, Portugal
}

Received: November 18, 2000; Revised: April 27, 2001

\begin{abstract}
Several techniques can be used to improve surface properties. These can involve changes on the surface chemical composition (such as alloying and surface welding processes) or on the surface microstructure, such as hardening and melting. In the present work surface melting with a $3 \mathrm{~kW} \mathrm{CO} 2$ cw laser was done to alter surface features of an AISI 304 stainless steel. Microstructure characterisation was done by optical and scanning electron microscopy. Vickers and Knoop microhardness tests evaluated mechanical features after surface melting. Phase transformation during rapid solidification is analysed and discussed.
\end{abstract}

Keywords: austenitic stainless stell, laser surface melting, delta phase

\section{Introduction}

From the point of view of mechanical engineers, the purpose of surface treatments is to obtain better performance of the workpiece whenever it is submitted to wear and/or high temperature and/or corrosive media. Surface treatments enable to enhance the surface properties to answer any particular requirement, while the bulk of the workpiece keeps its structural properties. However for most applications the ideal surface is still being worked on. This is a continuos search as it can contribute to a reduction in costs, either by diminishing repairs or replacement of components. In these context laser surface treatments have gained scientific and industrial interest. A summary of the main laser surface treatments is shown in Fig. 1. Within the treatments that do not involve changes on the chemical composition laser hardening has found several application in industry ${ }^{1-3}$.

Laser surface hardening through surface melting is done using a focussed or near focussed beam. The surface to be melted is shrouded by an inert gas. Using this procedure one can obtain fine homogeneous structures due to the rapid solidification rates, little thermal penetration, result- ing in little distortion, smooth surfaces, reducing work after processing, process flexibility, due to software control, and possibilities in automation. Laser surface melting is of industrial interest for materials that do not harden through martensite transformation, such as cast irons, some stainless steels, titanium, tools steels, etc. Results in the literature show that laser surface melting results on enhanced wear properties and low fatigue resistance due to the higher level of residual tensile stresses (Steen 1991), when compared to other surface treatments.

The understanding of the metallurgical phenomenon involved on laser melting is quite important as it applies to several techniques which require shallow surface melting such as surface melting, alloying and cladding, or even laser welding.

\section{Experimental}

An austenitic stainless steel, AISI 304, $16 \mathrm{~mm}$ plate in an annealed condition, was submitted to laser surface melting. Chemical composition of the as received material is presented on Table 1. The laser used for the surface treatment was a CW $3 \mathrm{~kW} \mathrm{CO} 2$ laser, and an area of $100 \mathrm{~mm} \mathrm{x}$ 


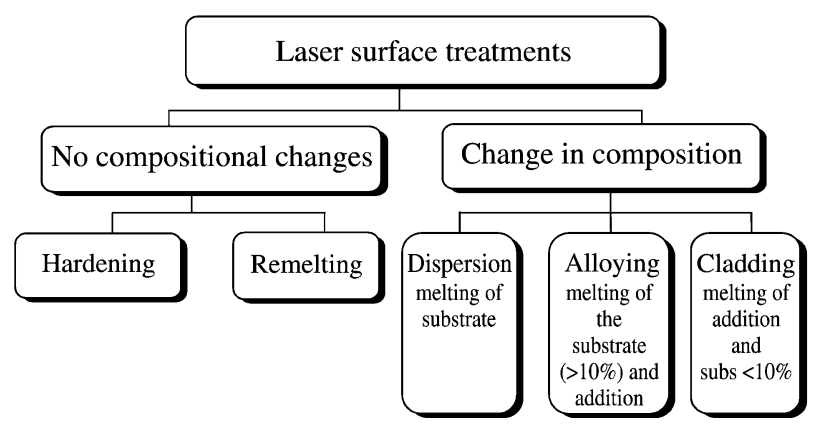

Figure 1. Laser surface treatments (adopted from Ref. 5).

$100 \mathrm{~mm}$ was melted by overlapping parallel tracks. Processing parameters are listed on Table 2.

Standard procedures were used to prepare metalographic specimens. Microstructure on the transverse section of the processed material, was analysed by optical and scanning electron microscopy. Mechanical features of the microstructure developed were evaluated by Vickers $(0.3)$ and Knoop (0.25) microhardness tests.

\section{Results and Discussion}

Microstructure of the as received material is presented on Fig. 2. The alignment of precipitates indicates the rolling direction. A general view of the transverse section of the material after laser surface melting is shown on Fig. 3. A smooth surface and a melting depth of $\approx 0.25 \mathrm{~mm}$ were obtained. Detailed observation of the melted region, revealed a fine dendritic structure, typical of the fast solidification rates involved on the process. Between the solidification structure and the substrate an unidentified structure was observed, Fig. 4. This structure is visible along the interface with the unmelted material with a thickness of $\approx 15 \mu \mathrm{m}$. Scanning electron microscopy showed the different features of the structures present on the material after laser surface melting, Figs. 5a, b and c. A "straight line" homogeneous interface between the melted and unmelted metal can be seen (Fig. 5a). It follows a region with an unexpected morphology (Fig. 5b), just before a fine columnar and dendritic solidification structure is identified (Fig. 5c).

Microhardness profile, $\mathrm{HV}(0.3)$ of the transverse section of the surface melted metal is presented on Fig. 6. No significant increase on hardness on the melted region was observed. Although the structure refinement at the surface could lead to an increase on the yield stress, the flow stress measured by the hardness test is not expected to change much particularly in a high strain hardening rate material like the AISI 304 stainless steel. In order to characterise the region along the interface with the unmelted metal, microhardness Knoop measurements were done. Knoop microhardness (HK0.25) profiles identify this region as a lower hardness phase, Fig. 7.

The microstructural features of the region near the interface with the substrate together with the lower hardness measured, indicate that it can be a region rich on ferrite $\delta^{6}$. Ferrite $\delta$ as revealed by metalographic analysis after

Table 2. Laser processing parameters.

\begin{tabular}{lc}
\hline Power & $2000 \mathrm{~W}$ \\
\hline Scan rate & $20 \mathrm{~mm} / \mathrm{s}$ \\
LASER beam diameter & $1.2 \mathrm{~mm}$ \\
Overlapping & $33 \%$ \\
Gas & $\mathrm{N}_{2}$ \\
\hline
\end{tabular}

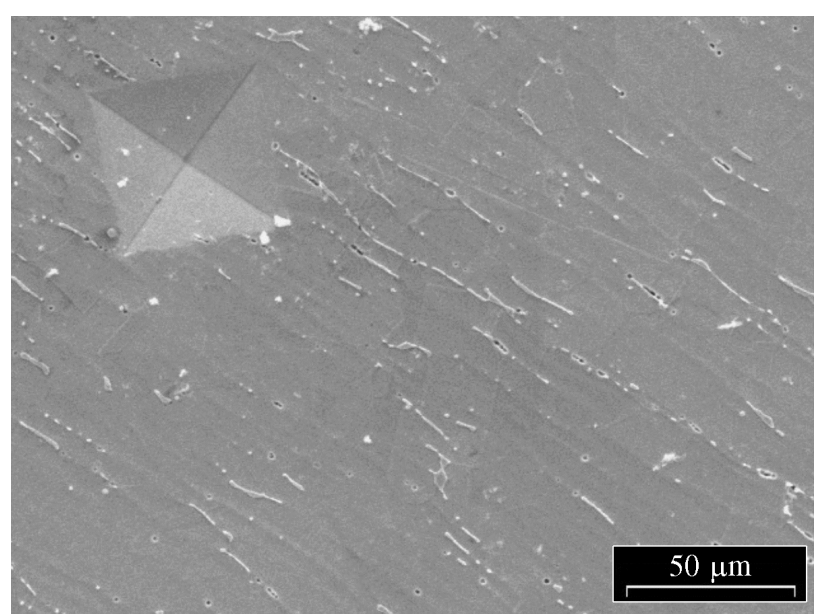

Figure 2. Microstructure of the as received AISI 304 stainless steel.

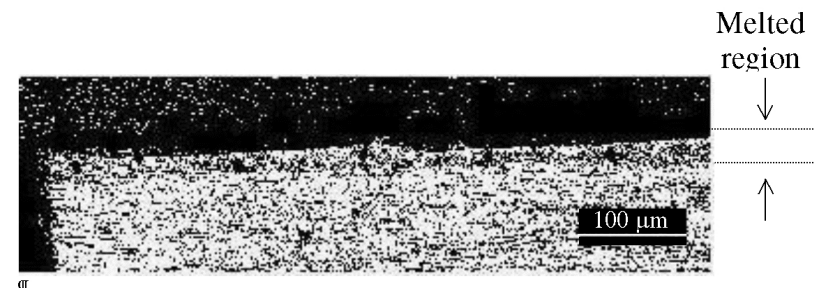

Figure 3. General view of the transverse section after laser surface melting $(5 x)$.

Table 1. Chemical composition of the as received AISI 304 stainless steel.

\begin{tabular}{ccccccccc}
\hline & $\mathrm{C}$ & $\mathrm{Si}$ & $\mathrm{Mn}$ & $\mathrm{P}$ & $\mathrm{S}$ & $\mathrm{Cr}$ & $\mathrm{Ni}$ & $\mathrm{Fe}$ \\
304 & $0.08(\mathrm{Max})$ & $1.0(\mathrm{Max})$ & $2.0(\mathrm{Max})$ & $0.045(\mathrm{Max})$ & $0.03(\mathrm{Max})$ & $18.00 / 20.0$ & $8.00 / 10.5$ & $\mathrm{Bal}$. \\
\hline
\end{tabular}


electrolytic etch, was identified parallel to the fusion line, Fig. 8. It is known that during the solidification of austenitic stainless steels, like AISI 304 the first phase to solidify is ferrite $\delta$, as the temperature drops below the peritetic transformation it tends to transform into austenite $(\gamma)^{7,8}$. The phase transformation $\delta \rightarrow \gamma$ depends on diffusion mechanism through a liquid or a solid phase, or in other words it depends on time. As such, the faster the temperature drops, less is the time available for the transformation $\delta \rightarrow \gamma$ to occurs and complete itself, therefore one would expect to

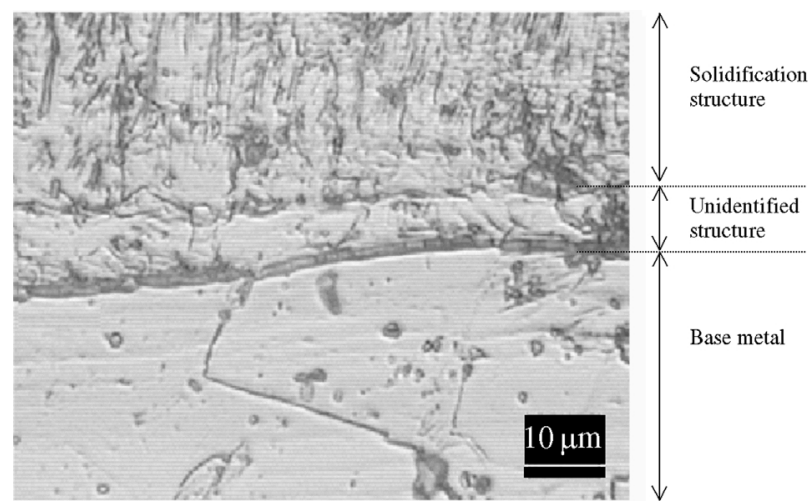

Figure 4. Microstructure features of the remelted material. find a certain amount of $\delta$ phase at room temperature. Results of GTAW and laser welding of AISI 304 stainless

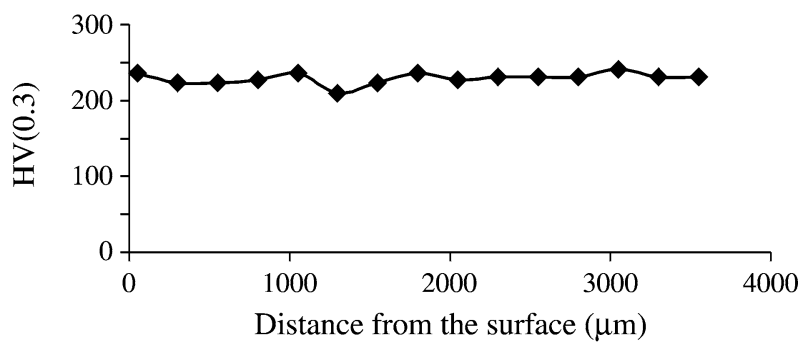

Figure 6. Vickers microhardness profile across the transverse section of the material submitted to laser surface melting.

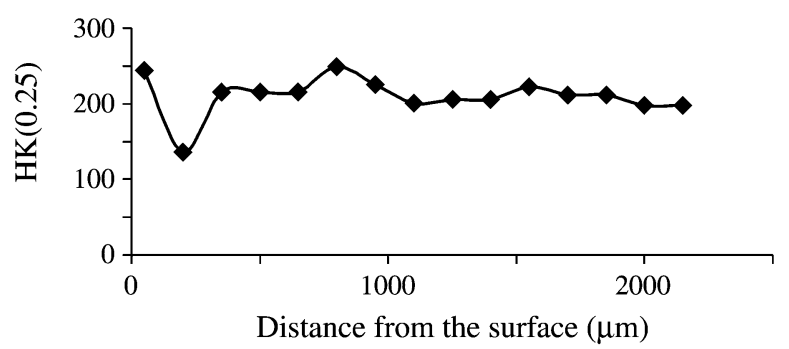

Figure 7. Knoop microhardness profile across the transverse section of the material submitted to laser surface melting.
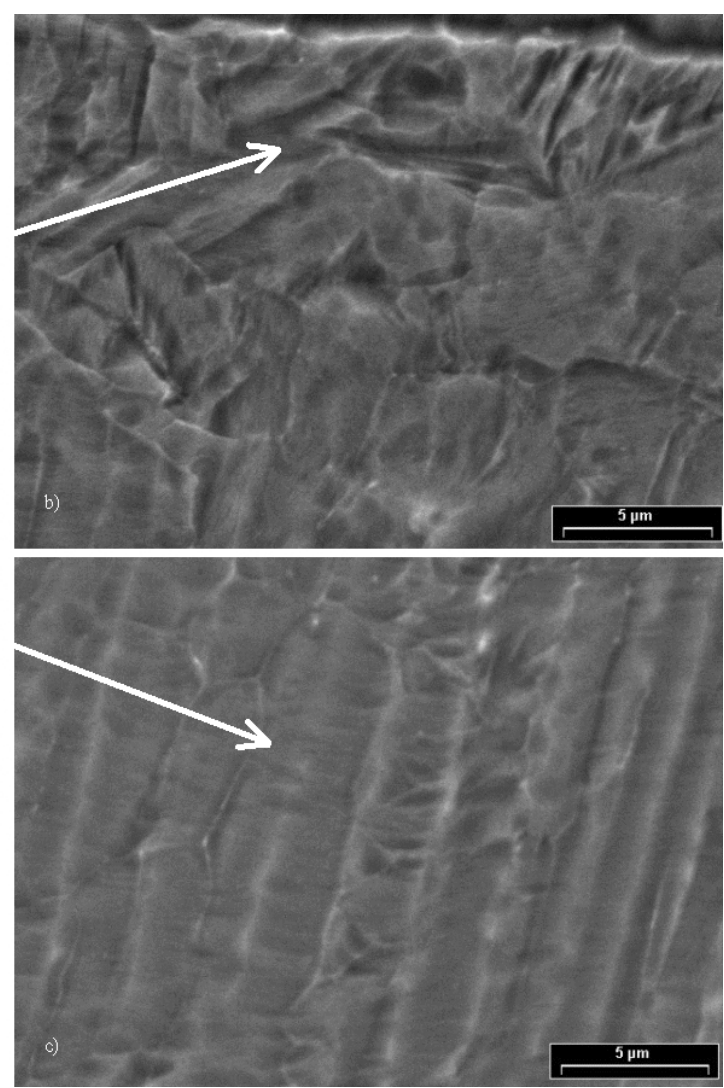

Figure 5. Microstructure of the melted region as observed under scanning electron microscope: a)general view of the transverse section melted material, b) detail of the structure found in the region near the interface between the melted and unmelted metal, c) detail of the solidification structure developed in the melt pool. 


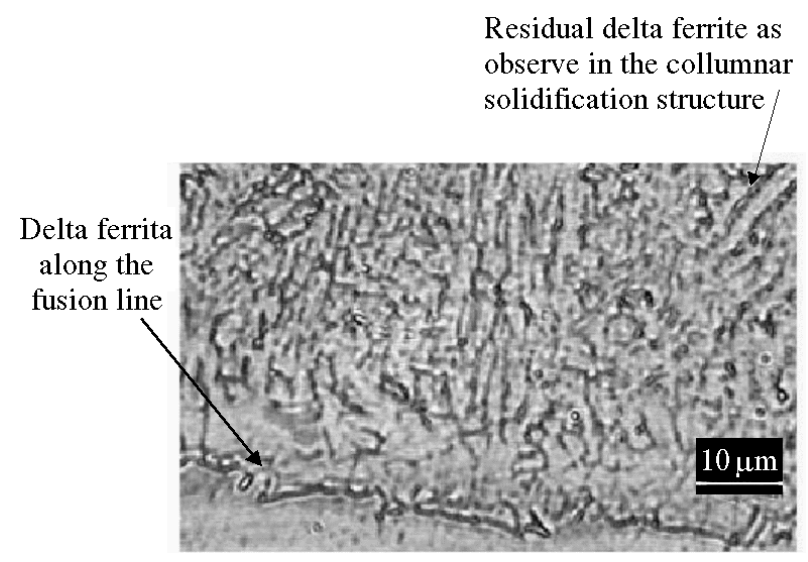

Figure 8. Interface between the melted and unmelted metal,ferrite $\delta$ is shown as dark coloration.

steel have shown a final microstructure consisting of an austenite $(\gamma)$ matrix with residual ferrite $\delta$ dispersed, as a consequence of a solidification sequence $\mathrm{L} \rightarrow \mathrm{L}+\delta \rightarrow \gamma$ $\delta \rightarrow \gamma \delta^{7,9,10}$. During laser surface melting due to the shallow melted region, a very steep temperature gradient is developed across the interface, or in other words, very high cooling rates are obtained. In the present work due the thickness of the plate used, $16 \mathrm{~mm}$, cooling can be considered unidirectional through the metal, as a consequence of the large ratio melted/unmelted material volume. These cooling rates are expected to vary across the melted region, being higher where the solidification starts, interface with substrate, and lower where it ends, external surface of the plate. Moreover the cooling effect of the protective gas used, $\mathrm{N}_{2}$, contributed to the temperature gradient developed on the material. Although $\mathrm{N}$ is a gamma stabiliser element, contributing to a reduction on the ratio $\mathrm{Cr}_{\text {eq }} / \mathrm{Ni}_{\text {eq }}$, the amount that is incorporated into the material is not sufficient to affect the solidification sequence.

As the influence of the presence of ferrite $\delta$ on the performance of AISI 304 stainless steel, is concerned, one could expected a higher resistance to corrosion and hot cracking and lower resistance to fatigue ${ }^{7}$.

\section{Conclusions}

Laser surface melting results on fine solidification structure, which can be attributed to the fast cooling rates, developed as a consequence of the temperature gradients generated in the material.

The fast cooling rates involved on the process resulted on a low hardness region, near the interface with the unmelted material, probably due to higher ferrite $\delta$ content.

\section{Acknowledgements}

The authors would like to thank the Laser Processing Laboratory of Instituto Superior Técnico, Lisboa/Portugal for processing the samples used in this work, in particular prof. Rui Vilar, and LACTEC for using their facilities of Scanning Electron Microscopy.

\section{References}

1. Brenner, B.; Reitzenstein, W. Laser hardening of turbine blades, Industrial Laser Review, p. 17-20, 1996.

2. Colaço, R.; Vilar, R. Laser surface melting of bearing steels, Laser Applications for Mechanical Industry, p.305-314, 1993.

3. Wallenweber, J. Laser Surface Heat Treating, Advanced Materials and Processes, v. 150, n. 6, 1996.

4. Steen, W.M. Laser Material processing, SpringerVerlag, 266p, 1991.

5. Bergmann, H.W., Kupfer, R. and Mller, D., Laser Hardfacing, $\mathrm{CO}_{2}$ Lasers and Applications II, p375390, 1990.

6. Brandi, S. Estudo da soldabilidade do aço inoxidável duplex Din W. Nr. 1.4462 (UNSS31803), Escola Politécnica da Universidade de São Paulo, 1992.

7. Welding Metallurgy of Stainless Steels, Erich Folkhard, Springer-Verlag, 1989, 279p.

8.Padilha, A.F.; Guedes, L.C. Aços inoxidáveis austeníticos - Microestrutura e Propriedades, Hemus, 170 p., 1994.

9. Neves, M.D.M.; Berreta, J.R.; Rossi, W.; Nogueira, G.E.C.; Wetter, N.U.; Vieira J.G.N.D. Soldagem de aço Inoxidável AISI 304 por laser de Nd:Yag, Soldagem \& Inspeção, n. 6, p. 8-16, 1999.

10.Zacharia, T.; David, S A.; Vitek, J.M.; Debroy, T. Heat transfer during Nd:YAG pulsed laser welding and its effect on solidification structure of austenitic SS, Metallurgical transaction A, v. 20A, p. 957-967, 1989.

11. Charschan, S.S. Guide to Laser Materials Processing, Laser Institute of America, ed: 1998, 265 p. 